\title{
MÉTODO INTUITIVO E TRABALHO DOCENTE: INCURSÕES NA REVISTA “A ESCOLA” (1906-1910)
}

\author{
Claudia Maria Petchak Zanlorenzi ${ }^{1}$ \\ UNICENTRO/UEPG
}

\author{
Maria Isabel Moura Nascimento ${ }^{2}$
}

UEPG

\section{RESUMO:}

Os estudos da História da Educação registram o papel estratégico desempenhado pela educação na formação do homem novo no início do século XX, de acordo com os ideais republicanos. A imprensa e a educação foram importantes instrumentos de divulgação desses ideais. O presente artigo tem por objetivo apresentar incursões realizadas na revista "A Escola", uma Revista do Grêmio dos Professores Públicos do Estado do Paraná, 19061910, em relação ao método intuitivo e o trabalho docente no Paraná, com o intuito de discutir como a revista foi utilizada de forma preponderante para a disseminação dos ideais vigentes. Primeiramente, apresentamos brevemente as ideias que permeavam a sociedade republicana, e na sequência as reflexões realizadas nesse periódico educacional paranaense.

Palavras-chave: imprensa, revista A Escola, método intuitivo, trabalho docente.

\section{METHODE INTUITIVE ET TRAVAIL DE L'ENSEIGNEMENT: INCURSIONS DANS LE MAGAZINE “A ESCOLA”(1906-1910).}

\section{RÉSUMÉ:}

L'es études sur l'histoire de l'éducation enregistre le rôle stratégique joué par l'éducation dans la formation de l'homme moderne au début du XX siècle, selon les idéaux républicains. La presse et l'éducation sont des instruments importants pour la diffusion de ces idéaux. Cet article vise à présenter les incursions effectués dans le magazine «A Escola», un magazine d'un Groupe des Enseignants du secteur public de l'État de Paraná em 1906 -1910, pour la méthode intuitive et le travail de l'enseignement dans le Parana, afin de discuter de la façon dont les magazine a été massivement utilisé pour la diffusion des idéaux actuels. Tout d'abord, nous présentons brièvement les idées qui imprégnait la société républicaine, et ensuite les réflexions a été effectuées dans cet périodique éducatif de Paraná.

Mots-clés: la presse, magazine A Escola, la méthode intuitive, le travail de l'enseignement.

\section{INTRODUÇÃO}

A produção da imprensa especializada em questões educacionais, ou seja, os periódicos educacionais, assim como atas, fotos, livros pontos, utilizados como fontes, são alvo crescente daqueles que se dedicam a pesquisar a história da educação brasileira. A partir de um material que possibilita uma análise dos diversos ângulos possíveis, pesquisas que se apropriam desse material aproveitam da sua riqueza para investigar o contexto educacional e as relações envolvidas nesse processo, como por exemplo, as propostas educacionais como referenciais e modelos pedagógicos. 
Todavia, essa materialidade e a veiculação à sociedade civil de um modelo pedagógico, incitam a um aprofundamento crítico, sobremaneira à cerca dos projetos educacionais do período de pesquisa, bem como do pensamento educacional vigente e as ideologias que permeavam esse processo.

O presente artigo tem por objetivo apresentar incursões realizadas na revista "A Escola" uma Revista do Grêmio dos Professores Públicos do Estado, 1906-1910, publicada com a colaboração de educadores de outras cidades e alunos do Gymnasio Paranaense e Escola Normal, em relação ao método intuitivo e o trabalho docente no Paraná.

Para tanto, primeiramente será realizada uma breve contextualização sobre os ideais republicanos, sendo a instrução pública considerada a peça primordial ao progresso da nova ordem. Em seguida, serão apresentadas reflexões sobre o método intuitivo e o trabalho docente, utilizando a revista " A Escola", como intuito de demonstrar como a imprensa foi utilizada de forma preponderante para a disseminação dos ideais republicanos.

\section{IDEAIS REPUBLICANOS: EDUCAÇÃO E FORMAÇÃO DO NOVO HOMEM}

Compreender a realidade social pressupõe o entendimento da totalidade e nesse ínterim as relações que os indivíduos estabelecem entre si. Produtos do seu tempo, tendo o trabalho como ato primeiro, os homens "[...] começam a se diferenciar dos animais tão logo comecem a produzir seus meios de vida" (MARX, 1979, p. 27).

Sendo assim, para o entendimento de qualquer que seja o objeto de uma pesquisa, o trabalho como estatuto ontológico enquanto processo permanente de objetivação do ser social, deve ser imperante, ou seja, como resultado real da atividade humana, com "[...] indivíduos reais, sua acção e suas condições materiais de existência[...]" ( MARX: ENGELS, 1979, p.18).

É pelo trabalho que o homem se humaniza, pois são as relações sociais de produção responsáveis pela formação do ser enquanto ser. A forma como se dão essas relações, ou seja, o modo como os homens produzem a sua existência, é fato primordial, dado que é a partir desse pressuposto que podemos inferir como os homens pensam, como se reconhecem, como se organizam e como transmitem suas ideias.

A partir do exposto podemos afirmar que a depender como os homens estabelecem as relações de produção para sua sobrevivência, assim se constituirá a sua formação, ou mais, como irá disseminar seu sistema de ideias, a ideologia.

A produção dessas ideias, das representações e da consciência está ligada diretamente com a atividade material e o intercâmbio dos homens, pois não "[...] é a consciência que determina a vida, mas sim a vida que determina a consciência" (MARX; ENGELS, 1979, p. 26).

Tais ideias representam o modo como essa realidade aparece ao homem e, se, por acaso, esta representação não demonstra a realidade efetiva é conseqüência do modo limitado de agir deste homem e das relações limitadas que surgem a partir disso. 
Como exemplo desse processo de ideologização, temos os ideais republicanos discutidos e difundidos após a Proclamação da República, que pretendiam produzir um novo Brasil, levando em conta o crescimento da economia, pela comercialização do café e o início da industrialização.

Esse movimento se desenvolve inicialmente nos principais centros do país, aos poucos se expande para os demais centros urbanos e capitais dos Estados. A sociedade brasileira ao transformar sua economia e a estrutura jurídica- política gerou efeitos ideológicos que vão se disseminando.

A estrutura jurídico-político instaurada, no plano nacional, entre 1888 e $1891,[\ldots]$ vai permitir a difusão progressiva do trabalho assalariado na formação social brasileira e, conseqüentemente, a implantação de relações capitalistas de produção (SAES, 2001, p. 102).

Com as relações e o modo de produção capitalista e os efeitos ideológicos advindos dos valores que regulam e moldam a estrutura social ${ }^{3}$, busca-se manter a coesão social. Desta forma, inaugurava-se um tempo de modernidade e progresso, transformando não só as relações entre os cidadãos, mas também no espaço geográfico. Entretanto, o que ainda se via era uma continuidade do predomínio dos que detinham os meios de produção.

O final do século XIX e início do século XX foram marcados pela urbanização da sociedade e, ao longo desses anos, inúmeras foram as transformações que ocorreram na produção, na distribuição, na troca, no consumo e nas relações sociais. A dinâmica social e espacial deste período é caracterizada pelo "modo de vida urbano". Assim, surgem outros padrões de comportamento, expectativas e um novo sistema de valores da civilização urbano-industrial.

A urbanização e o desenvolvimento industrial aos poucos foram alterando a feição tradicional das cidades e inicia o processo de desarmonia entre cidade e campo. A sociedade brasileira caracterizada pelo modelo agrário comercial, aos poucos passa para o urbano industrial, instaurando-se o desejo pela modernidade, e mais, se adequando às relações de produção instauradas naquele contexto. Marca dessa época, o moderno significava a instauração de uma cultura urbana, baseada em países como Estados Unidos, Inglaterra e França, num processo de transplante cultural.

No Paraná, essa ânsia pela modernização pode ser identificada em Curitiba, em 1913, quando o governo, seguindo o mesmo trem civilizatório, aprimora os serviços básicos como irrigação, limpeza pública, água e esgoto. Por todo "o plano urbano, ruas se abrem e se pavimentam; edificações se elevam, ostentando uma arquitetura inovadora, [...] por toda urbem, até fora do seu quadro, valorizam-se os terrenos e surgem novas construções" (TRINDADE, 1996, p. 19).

Essas ações correspondentes a um movimento amplo introduzem aspectos ideológicos refletidos na educação e "[...] é diante desse quadro de transformações - tanto no nível dos setores econômico, político, social, quanto no nível cultural- que se deve analisar a escolarização, nas mais variadas facetas"(NAGLE, 1974, p. 99). A escola assim, principalmente a primária, é utilizada como veículo de reprodução dos objetivos maiores da nação e como transmissora da mensagem patriótica e civilizatória a todos os cidadãos ${ }^{4}$ que ao mesmo tempo, sendo reprodutora, oportuniza a escolarização à população com o discurso de igualdade . 
Essa situação expressa a ideologia reproduzida pela escola, que oculta a realidade e é determinada pela natureza econômica. Apresenta-se com vida independente, com leis próprias, universais, como de interesse de todos, não as vinculando à realidade social.

É desta forma que se estabelece a análise sobre o processo de formação do homem, ou melhor, como se concebe a educação, pois essa "[...] é determinada, em última instância, pelo modo de produção da vida material" (LOMBARDI, 2010, p. 20).

A instrução pública significava a abertura para o progresso e um dos principais traços que marcavam a época, fator de transformação e de conformação social, pois “ignorancia e República são idéas que se repellem"(A ESCOLA, 1906, n. 1, p. 1). Um novo homem era necessário e com isso os parâmetros educacionais e a educação elitista, herdados do império, tornaram-se obsoletos. A educação escolar era colocada como uma medida de profilaxia social, na formação do "homem novo" (NORONHA, 2009, p. 167).

No Paraná, as campanhas de difusão da escola primária foram organizadas, pois "é base senão primordial, pelo menos fonte secundária onde o povo vae haurir a longos sorvos as luzes que aclaram o espírito de seus filhos."( A ESCOLA, 1906, n. 1, p.06). Surgem os primeiros grupos escolares 5 , pois "No ideário liberal dos republicanos paranaenses a instrução tinha um lugar de destaque, sendo compreendida como um instrumento indispensável para a consolidação da República" (NASCIMENTO, 2008, p. 170). Essa expansão do ensino foi sobremaneira um tema amplamente presente nos discursos das autoridades da época:

Todos repetem que o Estado, instruindo, se propõe formar cidadãos úteis ao lado de espíritos esclarecidos; educar intelectual e moralmente, preparar no indivíduo as condições necessárias a realizar, na Pátria, o lema de nossa bandeira: Ordem e Progresso. Ordem garantida pela edificação moral e progresso, provável, pela aquisição dos conhecimentos das leis naturais, a fim de atuar no mundo exterior (CERQUEIRA, A.P. Relatório do Director da Instrução Publica do Paraná apud TRINDADE; ANDREAZZA, 2001, p. 80).

O discurso liberal que imperava nessa época defendia como princípio a escola pública, laica, universal, sendo esse o caminho para o progresso individual, social e econômico, o que resultou na adequação do sistema educacional à ordem democrática. Defendendo os preceitos de individualidade e da liberdade, essa ideologia implicava no respeito às diferenças naturais, enfatizando o sucesso individual, considerando, é claro, os méritos individuais provenientes do esforço próprio. Esses preceitos liberais atendiam principalmente à elite intelectual, os ilustrados.

Embora saibamos que essas ideias liberais, como aspecto ideológico do capitalismo, defendiam a instrução pública com o objetivo de estabelecer a igualdade entre os cidadãos, essa tão pronunciada igualdade, todavia, era baseada no modelo imposto pelas elites - o modelo europeu, branco, masculino -, e ao mesmo tempo, em contrapartida, essa mesma escola passou a ser sinônimo de ascensão social.

Esse objetivo de ascensão social e de certa desocultação pode ser visto no número de grupos escolares que surgiram no Paraná ${ }^{6}$, ou seja, a visão que se tinha de projeção a partir do ensino, numa escola republicana que deveria ser humanista, democrática e 
progressista (TRINDADE, 1996, p. 22). Em contrapartida, essa expansão também era sinônimo de implantação da ideologia de um modelo civilizatório e nacionalista - com vistas à coesão social - e da naturalização da diferenças "ocultando as diferenças sociais pela proclamação do discurso igualitário" (CURY, 1989, p. 48). Podemos verificar essas ideias na Revista "A Escola”, na afirmação de que

É a escola primária uma instituição supernamente civilizadora. Officina de espírito infantil, é nesse recinto bemdicto que a intelligencia dos pequeninos seres, ainda não desabrochados para os conhecimentos, se vae desenvoluindo e inundando da luz cambiante e redemptora da instrução. ( A ESCOLA, 1906, n. 1, p. 2)

No final do século XIX, além da expansão do ensino público, também, compunham as preocupações dos dirigentes educacionais os temas da formação dos professores e os métodos de ensino empregados nas salas de aulas. Nesse período, o método mútuo ${ }^{7}$ foi progressivamente sendo trocado pelo método intuitivo, que se "manteve como referência durante a Primeira República sendo que, na década de 1920, ganha corpo o movimento da Escola Nova" (SAVIANI, 2007, p. 138).

Neste contexto, a imprensa teve um papel fundamental na formação de opiniões, como veículo de expressão dos projetos político-ideológicos, procurando assim sedimentar tais ideias na sociedade, transformando os interesses privados em interesses gerais. Era necessário que fossem propagados os moldes de ensino, ou melhor, os métodos de ensino e as práticas de organização escolar.

\section{MÉTODO INTUITIVO E TRABALHO DOCENTE}

Os estudos da História da Educação registram o papel estratégico desempenhado pela educação na formação do homem novo no início do século $\mathrm{XX}$, de acordo com os ideais republicanos.

Conforme os ideais liberais da sociedade, a instrução escolar seria o caminho para o progresso, sendo preciso assim atingir o maior contingente possível da população, tendo como tarefa alfabetizar para integrar o povo à política, moralizar o povo e higienizar espaços sociais (NORONHA 2009, p. 171). O objetivo era a difusão de uma ideologia que ocultando as diferenças sociais, proclamasse o discurso de igualdade e da homogeneidade, pois " [...] na ideologia burguesa liberal há a proposição de que todos os homens são iguais perante a lei e que, através do trabalho e de sua capacidade, todos podem vir a tornarem-se proprietários"(COVRE apud NORONHA, 2009, p. 167).

Diante dessa busca pela homogeneidade social, é possível inferirmos a manutenção das concepções veiculadas na revista, dando "aos pensamentos a forma de universalidade, representando-os como únicos, razoáveis, os únicos verdadeiramente válidos" ( MARX; ENGELS, 1979, p. 57).

Além da transmissão de novos conhecimentos por meio dos processos educacionais, a imprensa também foi utilizada como veículo de propagação da ideologia, visando principalmente orientar o trabalho docente e o método de ensino das séries iniciais 
no Paraná. A Revista “A Escola”, cumpriu o papel de veículo de propagação dessas ideias novas.

Das páginas desse periódico é possível verificar não apenas o cotidiano da capital paranaense, mas também as preocupações com o futuro da comunidade em virtude que era preciso

[...] estimular, por meio de leis e instituições de proteção e garantia a actividade individual dos cidadãos de hoje, educar as creanças no sentido de formar homens de caráter, dignos, aptos, enérgicos, resolutos, conscientes, para, com vantagem, aos luctadores de hoje, sucederem os de amanha; em suma, aperfeiçoar o indivíduo para aperfeiçoar a coletividade. (ESCOLA, 1907, n. 6, p. 67)

Os intelectuais e professores à frente da revista "A Escola" colocavam-se como referenciais, promulgando a ideia de uma educação moderna, porém sem ultrapassar a visão aparente da suposta harmonia, ou seja, sem uma análise das verdadeiras relações sociais contraditórias que permeavam a sociedade republicana e do ocultamento de como essas relações eram produzidas.

A carência de escola para a formação de professores, fazia com que manifestassem o "[...] desejo ardente de aperfeiçoar-se mais e mais"(A ESCOLA, n. 1, p. 10), de forma que a Revista "A Escola" se tornou no meio mais efetivo e rápido para a ampla divulgação dos ideais propostos pelo grupo, para a manutenção da maneira de pensarem, na ressonância de seus ideais e ainda como ecos das ideias que ressoavam no movimentos mais amplo da sociedade.

Esta publicação deve tornar-se o elo cohesivo dos professores, ministrando também ensinamentos que não só recordem aos mestres os ensinamentos recebidos, ampliando-os de acordo com os dados da Pedagogia Hodierna; como orientem aquelles que na Escola Normal se habilitam ao magistério. A escola só pode ser uma revista didática. (ESCOLA, 1906, n.07, p. 119)

Sendo assim, os intelectuais e professores a frente da revista, "em prol das ideas liberais" (ESCOLA, n.07, p. 135) em certa medida, detinham os instrumentos de conhecimento, ou seja, os meios de produção intelectual, cabia então aos demais professores reproduzir de forma acrítica o que era proposto por esses ditos guias esclarecidos, ou melhor, figuras profissionais capazes e impregnadas de "espírito burguês"(CAMBI, 1999, p. 408).

A questão da educação, na revista "A Escola", se sobressai como mecanismo de promoção social dos indivíduos e de progresso para o país, principalmente a educação primária, pois o valor "das nações é representado pela expansão intellectual de seus filhos, pelo fulgor de suas escolas, pela alteza, pelos princípios sãos e altruístas consignados na magnanima carta" (ESCOLA, 1906, n. 1, p.1). 
Desta forma, tornou-se oportuna a disseminação do método intuitivo ${ }^{8}$ para atender à ânsia por mudanças no ambiente educacional. Nos artigos da revista é possível analisarmos como o método intuitivo foi passado como modelo ideal de ensino, introduzindo processos de aprendizagem inovadores, como por exemplo, o enxerto abaixo quando explica que o método intuitivo: "Tem por base a lição das cousas Pestalozzi considerava-o tanto melhor quanto mais sentidos attrahia, entendida que os sentidos deviam todos ser educados ao mesmo tempo" (ESCOLA, 1906, N.07, p 123).

Essa preocupação dos escritores do periódico pode ser analisada quando afirmam que "instruir a mocidade não é inculcar-lhes um agregado de palavras, de phrases, de sentenças e de opiniões que se colheram de alguns autores; é abrir- lhe o entendimento para as cousas". (ESCOLA, 1907, n.8, p. 127) Era necessário uma "prompta solução" e essa poderia vir através das prescrições do método intuitivo. Urge modificar a forma de ensinar, sem uma investigação mais profunda das condições das escolas. Assim, esse método - pelos ecos do contexto mais amplo que propunham à educação do país - seria ideal, como é apontado na revista ao apresentarem uma proposta para o $3^{\circ}$ ano da escola Normal:

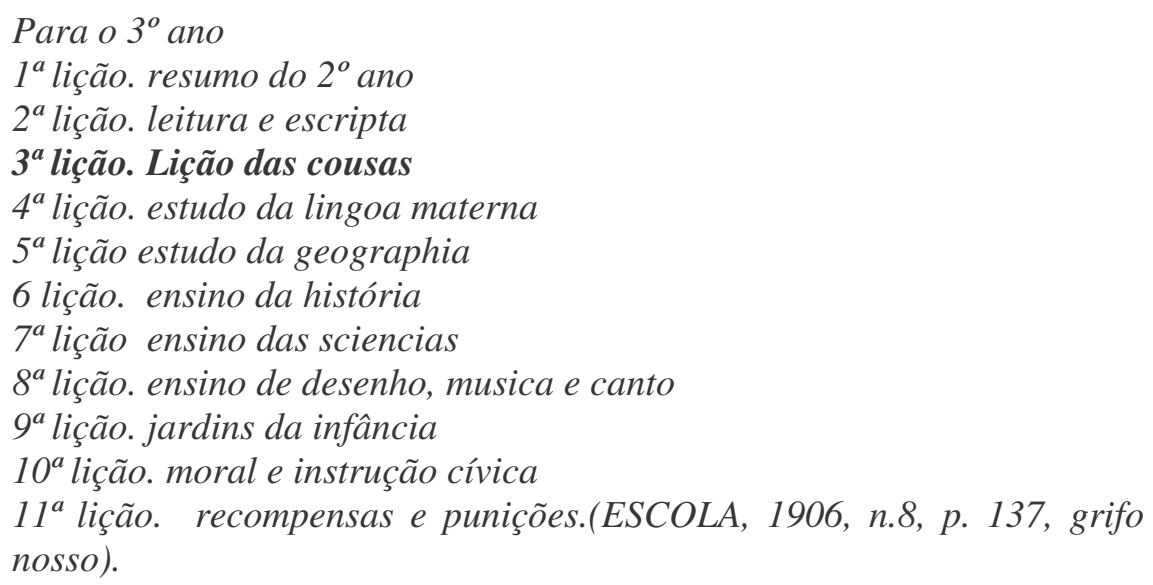

O método intuitivo tem como proposta promover situações de aprendizagem, que através da experiência o aluno pudesse aprender e não apenas memorizar o conteúdo. É interessante observar que esses preceitos, muito sedutores, sem uma verdadeira análise, continuam ainda presentes em nossos dias, nos discursos educacionais. Não é muito difícil encontrar em algumas "falas" de educadores contemporâneos, afirmações similares a essa,

A criança não deve se tornar um receptáculo da idéas de outrem, devendo interessadamente o professor habitual-a a agir por si mesma, a envidar esforços no intuito de descobrir o como e o por que das cousas; pois do contrário, mais tarde, na vida prática ella só pensará de accordo com que os outros pensarem e nunca terá liberdade de acção e de consciência (A ESCOLA, 1906, n.1, p. 09).

É oportuno analisar essas indicações e as relações com o método intuitivo. Destacamos primeiramente a afirmação " no intuito de descobrir e como e por que das cousas". No método intuitivo, que estava em foco nos Estados Unidos, o interesse deveria estar associado aos interesses das crianças e ao seu desenvolvimento intelectual. 
O educador deve saber como surge e se desenvolve esse psychismo tão rico e completo, deve saber como a creança entra em contacto com o mundo externo e sob que forma o mundo se faz congniscível. $O$ primeiro fenômeno psychico é a sensação, a reação do] organismo contra o meio [...] (A ESCOLA, 1906, n.10, p. 156).

Para tanto, eram necessários alguns processos de aplicação, ou melhor, seguir um modelo, que traria ordem e uniformização do ensino. Dessa forma, a educação deveria ser desenvolvida de forma prática a começar pela educação primária seguindo até a ampliação técnico - pedagógica da escola normal (NAGLE, 1974, p. 112).

É nessa perspectiva que podemos considerar que o periódico em questão teve um papel preponderante na disseminação de ideias específicas de professores aos professores paranaenses, o que nos incita a pensar sobre um proselitismo educacional, com o objetivo de formação docente, principalmente em um período em que a formação docente era escassa. É nesse contexto que a propagação do método intuitivo foi oportuno como modelo ideal e como uniformização, proclamando o discurso liberal de igualdade e da homogeneidade.

\section{CONSIDERAÇÕES FINAIS}

No início do século XX, tanto e educação como a imprensa foram utilizadas como instrumentos para a reprodução da ideologia que postulava a importância da ordem, da homogeneidade e da igualdade, qual seja os preceitos do liberalismo.

Tal fato pode ser visto na forma como a revista "A Escola" corroborava com um movimento mais amplo que via a educação como solução para a organização da sociedade brasileira com vistas à modernidade.

Os modelos que eram propostos na revista, como por exemplo, o método intuitivo, tinham por finalidade organizar e, até certa medida, impor um modelo pedagógico com vistas à formação do trabalho docente. A veiculação desse pensamento demonstra o caráter universalizador próprio de uma ideologia liberal necessária ao modo de produção capitalista.

A partir da análise desse periódico e do que era veiculado e a que era vinculado que podemos inferir o quanto a imprensa é uma rica fonte para analisar e estabelecer as relações por meio dos discursos expressos nos idos da sociedade republicana. Observa-se, então, a importância da imprensa enquanto mediadora para esse processo e um eficaz método de propagação de pensamentos e dos grandes debates do contexto.

\section{REFERÊNCIAS}

A ESCOLA: Revista do Grêmio dos Professores Públicos do Estado, 1906-1910. Acervo Biblioteca Pública do Paraná: divisão estadual.

CAMBI, F. História da Pedagogia. São Paulo: Editora UNESP, 1999.

CURY., C. R.J. Educação e contradição. São Paulo: Cortez/ Autores Associados, 1989.

LOMBARDI, J.C. Educação e ensino em Marx e Engels. Germinal: Marxismo e Educação em debate.v.2, n 2, 2010. 
MARX, Karl \& ENGELS, Friedrich. A ideologia alemã I. Lisboa: Editora Presença, 1979. NAGLE, J. Educação e Sociedade na Primeira República. São Paulo: EPU/MEC;Edusp, 1974.

NAScimento, M. I. M. A Primeira Escola de Professores dos Campos Gerais-PR. Ponta Grossa: Editora UEPG, 2008.

NORONHA, O. M. Educação e trabalho no contexto histórico da formação da Primeira República no Brasil (1889-1930). In: Navegando na História da Educação Brasileira: 20 anos do HISTEDBR. José Claudinei Lombardi; Dermeval Saviani (orgs.) Campinas, SP: Autores Associados: HISTEDBR, 2009.

SAES, Décio. República do Capital. São Paulo: Boitempo, 2001.

SAVIANI, D. História das idéias pedagógicas no Brasil. Campinas: Autores Associados, 2007

TRINDADE, E. M. C. Clotildes e Marias: mulheres de Curitiba na primeira

República. Curitiba: Fundação Cultural, 1996.

TRINDADE, E. M. C.; ANDREAZZA, M. L. Cultura e Educação no Paraná. Curitiba: SEED, 2001.

Notas:

\footnotetext{
${ }^{1}$ Professora colaboradora do Departamento de Pedagogia UNICENTRO- Campus Irati. Mestre em História da Educação, doutoranda em História da Educação (UEPG), membro do grupo de Pesquisa HISTEDBR Campos Gerais. aecmari@gmail.com

2 Professora da Universidade Estadual de Ponta Grossa-PR - UEPG, Coordenadora do Grupo de pesquisa História e Sociedade nos Campos Gerais-PR (HISTEDBR -UEPG)
}

3 Para Saes ( 2001, p. 97) os valores que regulam seriam os valores jurídicos, no direito aplicado às relações econômicas e sociais; já os valores que inspiram seriam os imperantes na organização interna do Estado, sendo que os dois produzem efeitos ideológicos.

4 Nagle (1974, p. 100) afirma que para verificarmos esse fato é necessário situar os movimentos intitulados pelo autor como entusiasmo pela educação e otimismo pedagógico, sendo o primeiro a crença na multiplicação das instituições escolares e disseminação da educação escolar como fator para o progresso nacional e o segundo a crença em determinadas formulações doutrinárias para formação do novo homem brasileiro.

5 Para saber mais sobre a criação dos grupos escolares ver: NASCIMENTO, M.I.M. A Primeira Escola de Professores dos Campos Gerais - PR. Ponta Grossa: Editora UEPG, 2008.

${ }^{6}$ Para termos uma noção da expansão dos grupos escolares Trindade e Andreazza ( 2001, p. 81) afirmam que no distrito da capital , “[...] as três únicas edificações exclusivamente destinadas ao ensino em 1893 multiplicaram-se, em 1916, em dez grupos escolares e, aproximadamente, em vinte e cinco escolas isoladas".

${ }^{7}$ Método mútuo "se baseava no aproveitamento dos alunos mais adiantados como auxiliares do professor no ensino de classes numerosas”(SAVIANI, 2007, 138).

${ }^{8} \mathrm{O}$ método intuitivo, conhecido como lições de coisas, foi concebido com o intuito de resolver o problema da ineficiência do ensino diante de sua inadequação às exigências sociais decorrentes da revolução industrial que se processara entre o final do século XVIII e meados do século XIX. Ao mesmo tempo, essa mesma 
revolução industrial viabilizou a produção de novos materiais didáticos como suporte físico do novo método de ensino. Esses materiais, difundidos nas exposições universais, realizadas na segunda metade do século XIX com a participação de diversos países, entre eles o Brasil, compreendiam peças do mobiliário escolar; quadros negros parietais; caixas para ensino de cores e formas; quadros do reino vegetal, gravuras, cartas de cores para instrução primária; aros, mapas, linhas, diagramas, caixas com diferentes tipos de objetos como pedras, metais, madeira, louças, cerâmica, vidros; equipamentos de iluminação e aquecimento; alimentação e vestuário etc. (SAVIANI, D. Verbete: Método Intuitivo In: LOMBARDI, J. C.; SAVIANI, D. ; NASCIMENTO, M.I. M. (Orgs.). Navegando pela história da educação brasileira. Campinas: Gráfica FE: HISTEDBR, 2006, p. 1-23. Disponível em: <http://www.histedbr.fae.unicamp.br/>. Acesso em: 31 jan. 2011)

Recebido em 23/02/2011

Aprovado em 30/03/2011 